\title{
What Causes Optimism Bias in Transportation Projects?
}

\author{
Mundhir AL Hasani, PhD Candidate \\ Bond University, Faculty of Society \& Design, Queensland, Australia
}

Doi: 10.19044/elp.v6no1a6

URL:http://dx.doi.org/10.19044/elp.v6no1a6

\begin{abstract}
The design, planning and implementation of large-scale infrastructure, particularly about transportation projects has proven to be an inherently difficult task due to several factors. The often-incorrect information provided for predicted costs and benefits has a significant impact on the economic feasibility of a project. This paper aims at examining the evidence and flow on effect of cost overruns and underperforming benefits in large-scale transportation projects. The causation for these elements will be analysed as well as methods aimed at alleviating these impacts to advance the overall delivery of projects of this nature.
\end{abstract}

Keywords: Cost overruns, infrastructure, transportation projects, optimism bias and decision-making.

\section{Cost Overruns and Benefit Shortfalls in Transportation Projects}

It is acknowledged that there has been little research about the actual costs and benefits of large-scale transportation infrastructure that has had such vast amounts of money spent on it in the modern age. A study carried out in 2002 examined transportation infrastructure projects spread over 20 countries adding up to a combined total of US $\$ 90$ billion between the years of 19281998 (Flyvbjerg et al., 2002). It found that in roughly a third of cases (28\%) the actual construction costs were higher than forecast and that $90 \%$ of projects had experienced cost overruns. The common theme running between the projects (258 in total) was that the associated costs were often underestimated. In a somewhat troubling finding, it was registered that there was no improvement in the overall accuracy of cost estimation during the 70-year period. The authors of the study concluded that the decision-making process employed in large-scale transportation infrastructure is disingenuous in a high number of projects (Flyvbjerg et al., 2002).

Within this study, it was noted that it was not just construction costs that are incorrectly forecasted. With most transportation projects within the 
study, the feasibility of the project draws heavily on the benefits associated with customer demand and utilisation forecasts. Forecasts of this nature are the basis for the environmental and socio-economic assessment of large-scale transportation infrastructure (Flyvbjerg, 2007; Huo et al., 2018; Love et al., 2016). Noteworthy examples of large-scale transportation infrastructure projects with significant cost overruns and a noticeable benefit deficit include the Channel Tunnel linking the United Kingdom with mainland Europe (via France). It came in over budget $80 \%$ for construction costs despite the private owner informing investors that $10 \%$ for overruns would be a sufficient contingency for construction costs. Another infamous example for cost overruns is the Denver International Airport that came in close to 200\% over budget (US\$1.7 billion quoted - US $\$ 5.1$ billion actual cost) in combination with passenger traffic only being $55 \%$ of the forecasted use, in its first calendar year of operation (Flyvbjerg, 1996).

\section{The Effect of Inaccuracy in Forecasting}

It is evident in the current economic climate that the inaccuracy of forecasts that culminate in such significant cost overruns and benefit deficits pose stakeholders, investors and key decision makers with some problems when assessing the viability of a new project (Flyvbjerg et al., 2002; Wang et al., 2018). In a practical sense, it is known that cost overruns are generally tied to delays in work, as the securing of surplus funds is often a lengthy process and may be exacerbated by the need to renegotiate and gain re-approval for the project. Because many projects of such a large scale are debt financed with extensive construction periods, they are particularly susceptible to impacts from delays, which compound into further debt through interest payments and an extension of the remuneration period. In conjunction with large cost overruns and benefit, deficits are the tendency it must undermine elements of the project such as policy, planning, implementation of policy and general operations. This is due to projects that require a constant process of reapproval cause a significant amount of 'noise' or debate, leading to an increase in pressure amongst the stakeholders tied to the project.

These factors accumulate as the project increases in size; cost overruns and benefit deficit accrue in real terms, meaning they carry more consequence. Some of these large-scale infrastructure projects place such a burden on their national economies that cost overruns and benefit deficits from an individual project may have a negative impact on national budgets or even place the finances of the country in a volatile or unstable state. An example of this was the sufferance of the credit rating of Greece after the benefit deficit of the 2004 Athens Olympics struck its economy. The desire to avoid financial stress on both a national and regional scale has been at the forefront of reforming 
planning techniques in relation to large-scale infrastructure projects (Flyvbjerg, 2007).

\section{What Causes Cost Overruns and Benefit Deficits?}

Errant decision-making on large-scale transportation infrastructure projects is recognised as having three main categories. The industry standard would be to facilitate improvement in this process, but for this process to occur, the causes for the inaccuracy of the forecasts must be assessed further. The categories divided into psychological, technical and political-economic (Dudley \& Banister, 2018).

In assessing the impact that technical explanations have had on cost overruns and benefit deficits in relation to decision-making, it is evident that technical issues arise when utilising flawed forecasting techniques. Contributing factors such as insufficient data or when the forecasters are not experienced in the area being examined also play a significant part (Flyvbjerg et al., 2002).

Optimism Bias or psychological explanations account for the majority of cost overruns and benefit deficits. In defining optimism bias, it is recognised as being the disposition for humans to be overly optimistic when predicting or forecasting the outcomes of future actions. Because of this, the decisionmaking process is often based on an inaccurate forecast (underestimated costs and overestimated benefits) instead of on the balance of the expected gains, losses and probabilities. As a consequence of this those in charge of the largescale transportation infrastructure projects approves projects that are almost certain not to be delivered on time, on a budget or deliver the benefits prescribed (Dudley \& Banister, 2018; Flyvbjerg et al., 2005).

The political-economic aspect of the problem identifies the planners and promoters as intentionally overemphasising the benefits while underestimating costs when predicting the outcomes of large-scale transportation infrastructure projects. Actors in the political-economic realm do this to ensure that their projects gain the necessary approval and funding needed (Dudley \& Banister, 2018).

A study into the way in which these three categories interact found that despite their being the presence of technical errors within the forecasting of issues it did not account for the empirical data gathered (Flyvbjerg \& COWI, 2004). The researchers pointed instead to the interplay between the psychological and political-economic categories, as the data was nearly always presented in the same way, with an underestimation of costs and an overestimation of benefits. This pointed to the issue of being an inbuilt mechanism of bias within the decision-making process and not simply unexplainable inaccuracy (Szafranko, 2017; Wachs, 1989). This is supported by the notion that if the inexperience of forecasters or flawed forecasting 
techniques were the main causes, then an increase in the accuracy of forecasts could be expected as more experience was accrued, and the process of refining techniques and models was undertaken.

Flyvbjerg agreed that the psychological aspect accounted for optimism bias while the political-economic impact accounts for the elements of strategic misrepresentation encountered. This combination of these elements can effectively explain why large-scale transportation infrastructure project costs are consistently higher than forecast while actual benefits are considerably lower (Flyvbjerg, 2007; Flyvbjerg et al., 2018).

\section{Accounting for Optimism Bias in the Decision-Making Process}

It is well recognised that projects or proposals of an optimistic nature are generally approved, while proposals of a pessimistic nature are often suppressed or aborted. From an individual sense optimism bias within each employee can be reinforced and bound together by the prospects of a project. Ultimately this validation from within an organisation causes both individuals and organisations to make imperfect decisions on large-scale transportation infrastructure projects based almost solely on optimism (Love et al., 2016; Wachs, 1990). This process results more often than not in underestimated costs and inflated benefits to the project (Flyvbjerg, 2016). In reviewing when optimism bias was most easily identified it was noted that it was during the appraisal stage that included the business case. It was found to decrease as the project progresses as mitigation strategies and other risk management techniques are utilised. While some within the industry label these distortions, made almost explicitly for political reasons a lie, it is rarely deemed as such (Flyvberg et al., 2002).

Underestimated costs + Overestimated benefits = Funding (Flyvbjerg, 2009, p.353)

This simple equation is found to be true when discussing misrepresentation, or intentional optimism bias appears not only like an inbuilt industry mechanism but a certain aspect of developing large-scale transportation infrastructure projects.

\section{Methods for Liming the Impact of Optimism Bias}

In his research on the subject, Flyvbjerg has suggested that the combination of optimism bias (psychological) and strategic misrepresentation (political-economic) of cost overruns and benefit deficits have merit. In a realworld setting, it is often challenging to differentiate between what is an unintentional delusion (optimism bias) and intentional deception (misrepresentation) (Flyvbjerg, 2009, 2016, 2018). In a retrospective light, the detection of political-economic pressure increases the likelihood of strategic misrepresentation. In the same light if there is a lack of political-economic 
pressure then the likelihood of optimism bias being the cause for unforeseen cost overruns and benefit deficits increases. This leads many analysts to believe that the two types of explanation optimism bias (psychological) and misrepresentation (political-economic) accompany each other and more often than not may exist within an individual project.

The development of a more efficient method for forecasting is the most known way in which the decision-making process for large-scale transportation infrastructure projects. Reference class forecasting aimed at mitigating or reducing the cause of optimism bias was developed by Lovallo and Kahneman (2003). It is intended to counteract the type of unintentional cognitive bias found in the majority of human forecasting.

Reference class-forecasting forces the project planners to take an exogenous view of the project. This forces the planners to take into account projects of a similar nature that have been previously completed, essentially comparing it against a database of previously completed projects. This allows for the real term costs and benefits incurred against the previous project plans against which the current project plan is to be in direct comparison.

The most advantageous element of reference class forecasting is that it circumvents the psychological impact of human bias (optimism bias) as well as limiting the impact of strategic misrepresentation. This method removes from the forecast the uncertainty of specific events that might impact on the project, but rather allows for the project to be compared directly with the outcomes from the database of previously completed projects. This eases the pressure on the project planner's as they are no longer required to speculate on the possibility of uncertain events. Thus, the circumvention of human bias is facilitated (Flyvbjerg, 2006; Huo et al., 2018; Love et al., 2016). While this exogenous view of forecasting may not allow for the prediction of scenarios outside of the reference class, for the majority of large-scale transportation infrastructure projects, it will inevitably prove more efficient for forecasting real term costs and benefits (Flyvbjerg \& COWI, 2004; Szafranko, 2017).

Instances of reference class forecasting being utilised are headlined by the British Department of Transport including it in their publication of 'Procedures for Dealing with Optimism Bias Transport Planning' (Flyvbjerg \& COWI, 2004). This publication provides a recognised format for the reference class method as an essential element of project appraisal for all large-scale transportation infrastructure projects. It forces project planners to facilitate with the appraisers in order to generate precise, empirically driven amendments to the forecasts provided for a project projected costs and benefits as well as construction period. All these adjustments are to be based on previously completed projects of a similar nature, with exceptions to be made to allow for the specific unique features of the project. In strengthening the case for the use of reference class forecasting, the American Planning 
Association (APA) has given the method formal endorsement, advocating that project planners utilise the method and not to rely on standard forecasting methods when forecasting for a large-scale transportation infrastructure project (APA, 2005).

To counteract the non-accountability of both the public and private sector several processes have been put forward. These processes include forcing forecasters and promoters to carry the full risk attached to their forecasts essentially. To safeguard transparency in this process the forecasts provided should be further analysed by a board of independent industry professionals.

Within the large-scale transportation infrastructure, project construction industry practices have arisen that have had a definite amount of success in forecasting more accurate costs and benefits. The principal method involves structuring of contracts such that forecasters and their organisations hold sole or shared financial responsibility any overrun of costs and for the deficit of benefits if they should so arise. This facilitates a better alignment of shared incentives and project vision (Flyvbjerg et al., 2008, 2016, 2018).

The second method is coined a Design-Build-Finance-OperateMaintain (DBFOM) contract. This contract compels the private sector to take full responsibility for the design, building (construction), financing, operation and maintenance of the transportation infrastructure on a long-term basis (commonly 20-30 years). At the expiration of this contract, the ownership of the facility is handed over to the correct government authority. This accountability of the contract addresses the majority of the issues that occur as a result of forecast inaccuracies (Flyvbjerg et al., 2009).

The last method involves a joint venture in risk allocation or a balance of risk sharing between the public and private investors. The investment of risk capital facilitates this into the project. This is usually accomplished by circumventing financing entirely by the public sector but rather through PPP arrangements, partnering the project or outsourcing the finances (Flyvberg et al., 2009). This compels the project financers (private lenders and shareholders) to analyse the prescribed costs and benefits of the large-scale transportation infrastructure project, increasing the prospect of exposing optimism bias or strategic misrepresentation.

This method has received large-scale support from a study completed by Mott MacDonald which revealed that conventionally financed projects contained a significantly greater level of optimism bias than methods financed in a manner above. "The variation between the publicly and privately managed projects is recognised as the relocation of project risks to the organisation best positioned to attain the best benefit to cost ratio while still maximising quality" (2002, p.12). 


\section{Conclusion}

The evidence indicating that cost and benefit forecasts utilised in the decision making the process for large-scale transportation infrastructure projects is overwhelming, with evidence indicating not just forecasts of a significantly inaccurate nature, but systematically misleading ones as well. This seemingly inbuilt industry mechanism poses a series of issues for those involved in the decision-making process as well as the other parties involved such as taxpayers, stakeholders and investors as they have to deal with the misallocation of assets (resources) placing significantly more pressure upon the feasibility of a project.

The main proponents for cost overruns and benefit deficits identified in Flyvbjerg's research are optimism bias and strategic misrepresentation. Also identified is the ability of these two explanations to coexist within the same project, despite this the approaches to mitigating their existence are divergent.

The prominent approach to mitigating optimism bias in environments where it is identified is by adopting more efficient forecasting methods. The industry-endorsed method of reference class forecasting, which utilises an exogenous view of project planning, has gained traction as the most successful method forecasting for large-scale transportation infrastructure projects. Its prominence has been garnered by successful integration within Europe and has the seal of approval from the American Planning Association as the recommended method of forecasting costs and benefits for large-scale transportation infrastructure projects. Despite this advance in forecasting methods in circumstances where there is a lack of motivation for parties to avoid strategic misrepresentation, the impact of the reference class method is diminished, save for it being used in conjunction with an increased sense of responsibility in mitigating such behaviour.

Models for amending this type of behaviour include restructuring government grants and placing forecasts provided for the project through an independent industry review process. In conjunction with this is the realignment of the finance methodology for large-scale transportation infrastructure projects. This can essentially be forcing the government as adopting the part of safeguarding the interests of the public, while project planners and investors carry a greater portion of the risk attached to the project. This is generally accomplished by the structuring of the project into a partnership or PPP arrangement or by outsourcing the risk to a suitable organisation.

In summation, it is evident that those in charge of project planning (forecasting and promotion) should be charged with the task of carrying the accepted risk of their forecasts. This would utilise the burden of an inaccurate forecast as a safeguard against optimism bias and strategic misrepresentation. 
Without this safeguard or methodology in place with all large-scale transportation infrastructure projects then issues most often connected with optimism bias and strategic misrepresentation will continue to be a mitigating factor in the success of large-scale transportation infrastructure projects.

\section{References:}

1. APA. (2005). Planners called to help end inaccuracies in public project revenue forecasting, Retrieved on 2 August 2018 from http://www.planning.org/newsreleases/2005/apr07.htm

2. Dudley, G., \& Banister, D. (2018). Expertise in decision-making for large infrastructure projects: from UK trunk roads to High Speed Rail 2. Transportation Planning and Technology, 41(5), 481-496. doi:10.1080/03081060.2018.1468969

3. Flyvberg, B. (2009) Survival of the unfit test: why the worst infrastructure gets built - and what we can do about it. Oxford Review of Economic Policy, 25(3),344-367.

4. Flyvbjerg, B. \& COWI. (2004). Procedures for Dealing with Optimism Bias in Transport Planning: Guidance Document. London: UK Department for Transport.

5. Flyvbjerg, B. (1996). Flyvbjerg, Bent, The Dark Side of Planning: Rationality and 'Realrationalität'. Seymour J. Mandelbaum, Luigi Mazza, and Robert W. Burchell, eds., Explorations in Planning Theory, New Brunswick, NJ: Center for Urban Policy Research Press, pp. 383-394. Available at SSRN: https://ssrn.com/abstract=2278431

6. Flyvbjerg, B. (2006). From Nobel Prize to Project Management: Getting Risks Right. Project Management Journal, 37(3),5-15.

7. Flyvbjerg, B. (2007). Cost Overruns and Demand Shortfalls in Urban Rail and Other Infrastructure. Transportation Planning and Technology, 30(1), 9-30.

8. Flyvbjerg, B. (2008) Curbing Optimism Bias and Strategic Misrepresentation in Planning: Reference Class Forecasting in Practice. European Planning Studies 16(1), 3-21.

9. Flyvbjerg, B. (2016). The Fallacy of Beneficial Ignorance: A Test of Hirschman's Hiding Hand. World Development, 84, 176-189. doi:https://doi.org/10.1016/j.worlddev.2016.03.012

10. Flyvbjerg, B., Ansar, A., Budzier, A., Buhl, S., Cantarelli, C., Garbuio, M., . . . van Wee, B. (2018). Five things you should know about cost overrun. Transportation Research Part A: Policy and Practice, 118, 174-190. doi:https://doi.org/10.1016/j.tra.2018.07.013

11. Flyvbjerg, B., Bruzelius, N. \& Rothengatter, W. (2003). Megaprojects and Risk: An Anatomy of Ambition. Cambridge: Cambridge University Press. 
12. Flyvbjerg, B., Holm, M \& Buhl, S. (2002). Underestimating Costs in Public Works Projects: Error or Lie? Journal of the American Planning Association, 68(3), 279-295.

13. Flyvbjerg, B., Holm, M. \& Buhl, S. (2005). How (In)accurate Are Demand Forecasts in Public Works Projects? The Case of Transportation. Journal of the American Planning Association, 71(2),131-146.

14. Flyvbjerg, B.; Garbuio, M \& Lovallo, D. (2009) Delusion and Deception in Large Infrastructure Projects: Two models for explaining and preventing executive disaster. California Management Review 51(2),170-193.

15. Huo, T., Ren, H., Cai, W., Shen, G. Q., Liu, B., Zhu, M., \& Wu, H. (2018). Measurement and Dependence Analysis of Cost Overruns in Mega transport Infrastructure Projects: Case Study in Hong Kong. 144(3), 05018001. doi:10.1061/(ASCE)CO.1943-7862.0001444

16. Love, P. E. D., Ahiaga-Dagbui, D. D., \& Irani, Z. (2016). Cost overruns in transportation infrastructure projects: Sowing the seeds for a probabilistic theory of causation. Transportation Research Part A: Policy and Practice, 92, 184-194. doi:https://doi.org/10.1016/j.tra.2016.08.007

17. Mott MacDonald. (2002). Review of Large Public Procurement in the UK. Study for HM Treasury, Retrieved on 2 August 2017 from http://www.hm-treasury.gov.uk/media/A00/D3/greenbook mott.pdf

18. Szafranko, E. (2017). Decision problems in management of construction projects. IOP Conference Series: Materials Science and Engineering, 251(1), 012-48.

19. Wachs, M. (1989). When Planners Lie with Numbers," Journal of the American Planning Association, 55, (4), 476-479.

20. Wachs, M., 1990, Ethics and advocacy in forecasting for public policy, Business and Professional Ethics Journal, 9, (1-2), 141-157

21. Wang, L., Xue, X., Zhao, Z., \& Wang, Z. (2018). The Impacts of Transportation Infrastructure on Sustainable Development: Emerging Trends and Challenges. International journal of environmental research and public health, 15(6), 1172. doi:10.3390/ijerph15061172. 